\title{
Designing Mobile Apps for English Vocabulary Learning
}

\author{
Bor-Tyng Wang
}

\begin{abstract}
Since the $21^{\text {st }}$ century, with the development of high technologies, such as Internet, tablets, and smartphones, there are more innovative ways to learn English. For example, people are able to use technologies to send messages, present ideas or share information anytime, anywhere. However, most of the mobile apps for English learning purposes in Taiwan are designed and presented in English interface. This is good for high level students, but the low level students may feel difficult and frustrated. Hence, the paper presents a pilot study and aims to develop a mobile app to improve college students' English vocabulary learning with both English and Chinese descriptions. The NGSL list is used as the content in the app, and the researcher designs twenty-four vocabulary learning units for students to use in one academic year. Students are expected to learn thirty words every week. Moreover, the words are presented both in English and Chinese because the target group is low-level students (CEF A2 level). In addition, the questionnaires were used to collect students' opinions toward the app. During this pilot study and with the use of mobile app, it is hoped that students' learning motivation can be increased and the self-study habits can be built.
\end{abstract}

Index Terms-English vocabulary learning, mobile apps, NGSL.

\section{INTRODUCTION}

Nowadays, when people get a new smartphone, most of them will download apps (applications) immediately [1]. Therefore, the educators sense this phenomenon and start to design thousands of apps for people to use in their daily life. For the past two decades, there are a lot of applications of educational activities on the Internet. Teachers and students in different areas can interact on the Internet ubiquitously [2]. Because of the huge impact of information technology, the learning style and learning environment have been changed [3]. In order to teach these digital natives, teachers need to understand how to inspire their learning motivation instead of forbidding them using tablets or smartphones [4].

In response to the global information era, countries all over the world are encouraging educators to use computer-assisted devices for educational purposes. However, why is it important to use digital resources in language learning [5]-[7]? Here are some possible answers.

1) It provides a connection between teachers and students. In the traditional classroom, teachers and students only communicate in the classroom. However, with the development of the Internet, they can communicate through instant messaging software, like email, Facebook, or Line.

2) Learning environment has been changed from the

Manuscript received November 12, 2015; revised January 19, 2016.

B.T. Wang is with the Foreign Language Center, Feng-Chia University, Taiwan (e-mail: btwang.tw@gmail.com). computer to the cloud computing [7], [8]. In the past, the multimedia with visual or audio functions are enough for teaching and learning. However, since the emergence of iPad, iPhone or other Android tablets, there are more choices of teaching and learning.

3) With the development of cloud computing and tablets, the course management system has also been developed [9], [10]. For example, there are many teachers use Blackboard or Moodle to integrate the handouts, syllabus, or students' learning portfolio.

As an English teacher, the appropriate digital resources can be adapted into language teaching. Hence, using apps in language learning is in line with current educational trend. Because the apps are portable and students can use them on their smartphones, it is easy to use without environmental limitation. So the paper aims to develop an English vocabulary learning app for college students in a private university in central Taiwan. The target group students' English level is about CEF A2 level and there are about 30 students who join this pilot study. Besides, the New General Service List (NGSL) is used as the main content of the pilot study and the researcher designs twenty-four units for students to use in one academic year. In each unit, there are about thirty words. At the end, the researcher wants to explore college students' attitude of the use of app in English vocabulary learning, and its potential value of self-study with apps after class.

\section{LITERATURE REVIEW}

Mobile learning is a student-centered approach, which also includes the theory of constructivism and cognitive theory in multimedia learning (CTML). Hence, in this section, m-learning, the constructivism, and CTML will be introduced.

\section{A. Mobile Learning}

There are many different definitions of "mobile learning" [11]-[13]. Some researchers say m-learning refers to learning while moving around or using mobile devices to learn. That is, no matter where the students are, if they have mobile devices, they can study ubiquitously. In summary, there are some advantages of using mobile devices in learning [11]-[13].

1) It is easier to share information: when people find any information, they can share it on the Internet.

2) Learning without space constraints: learning can be done ubiquitously. For example, students can study inside or outside the classroom.

3) Learning in the real context: students can observe or receive information and then interact with their peers on the Internet.

4) Recording students' learning portfolio: students' learning 
process can be recorded and this can be provided as a reference for individual learning.

Hence, we can understand that the classroom is no longer the only learning environment. Instead, the mobility makes students be part of the context and interact with their peers. So, for teachers, they need to apply mobile devices and design teaching strategies to help the students.

Finally, students' individual knowledge can be built, and he cannot only develop the critical thinking ability, but also enhance learning motivation and increase learning outcomes [14].

\section{B. Constructivism}

According to the concepts of constructivism, the purpose of education is to train students to be independent and self-directed [15]. Vygotsky pointed out the scaffolding theory, which emphasizes that teachers need to support students to accomplish the tasks [16]. There are three phases in the scaffolding theory, including modeling, support building and support fading. When students go through the three phases, they can build confidence, enhance comprehension ability, and increase their ability in independent learning and application. Moreover, when students use mobile devices to study, they also solve problems on their own. Therefore, the paper applies Vygotsky's idea and helps students to establish their vocabulary learning styles. Also, students are expected to apply what they have learned to the m-learning context.

\section{Cognitive Theory in Multimedia Learning}

Teaching design plays an important role in the curriculum. It needs to include the learning goals, learning outcomes, teaching methods and assessment methods. Nowadays, there are more and more multimedia being applied in teaching and some researchers indicate its relation with cognitive psychology [17], [18]. There are some important elements of multimedia learning, and they are summarized as follows [17], [18]:

1) The content of the material.

2) Using teaching methods to help students' learning.

3) Applying media, like texts or images to deliver content and methods.

4) Establishing new knowledge or skills to achieve individual learning goals.

The so-called cognitive theory in multimedia learning (CTML) refers to the process of sensory memory to working memory [17]. There are two possible ways: 1) from audio sounds to verbal representation and 2) from visual images to pictorial representation [17]. The assumptions of cognitive theory in multimedia learning and limited-capacity are the same, and they refer to a limited amount of working memory [17]. That is, the visual working memory can only hold one limited image, and the audio working memory can only hold one limited sound. Moreover, the assumptions of multimedia learning cognitive theory are consistent with active treatment, including active processing, selecting words, selecting images, organizing words, organizing images and integrating [19].

\section{RESEARCH DESIGN}

In this section, the design of the NGSL vocabulary app, and the questionnaire to investigate students' attitude toward the app are introduced.

\section{A. The Design of the NGSL App}

In order to encourage low-level college students' English learning motivation, the researcher designs an app which introduces NGSL words in both English and Chinese. Also, there is an example sentence followed by each word. A total of twenty four units are designed, and there are about thirty English words in each unit.

The Google's Android operating system was used in the app design in this research. The prototypes are shown in Fig. 1 and Fig. 2.

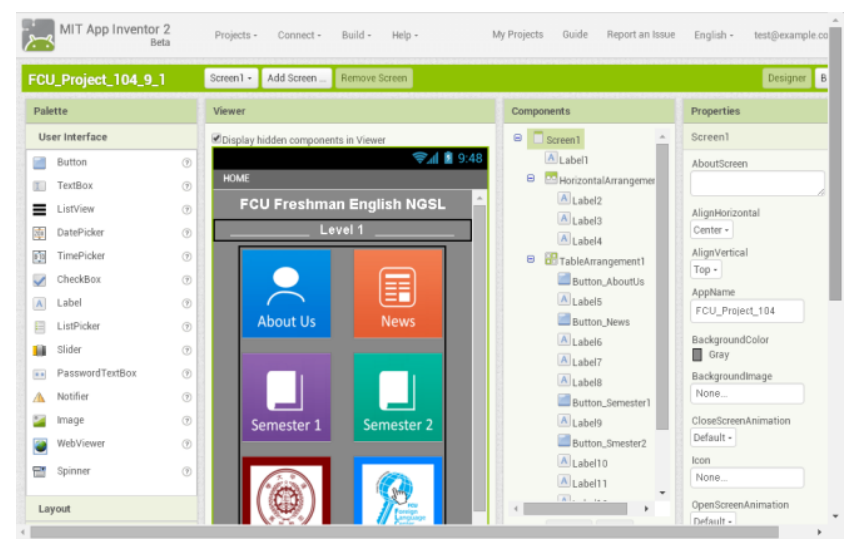

Fig. 1. App prototype 1.

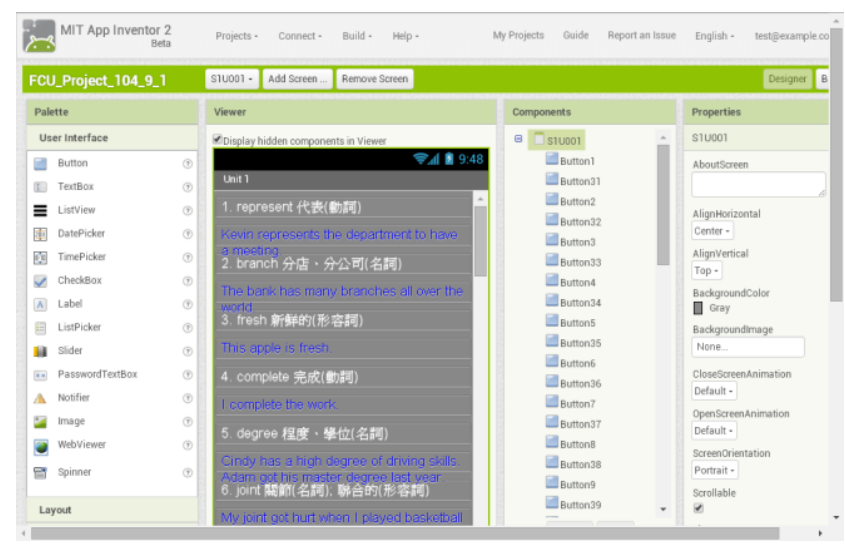

Fig. 2. App prototype 2.

With the Android system, the researcher can customize the look of the app. Hence, the researcher designed the homepage which includes the brief introduction of the app, news, two semester's word lists and two links to the school's website. The homepage is presented in Fig. 3.

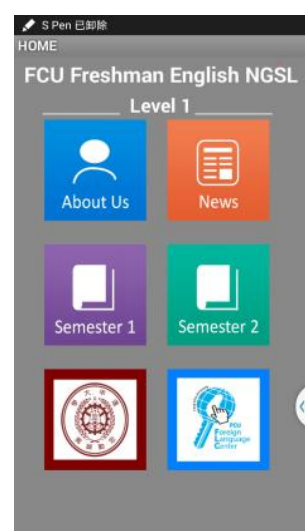

Fig. 3. The home page of designed app. 
After that, the researcher worked on the content and built the units in each semester which is shown in Fig. 4.

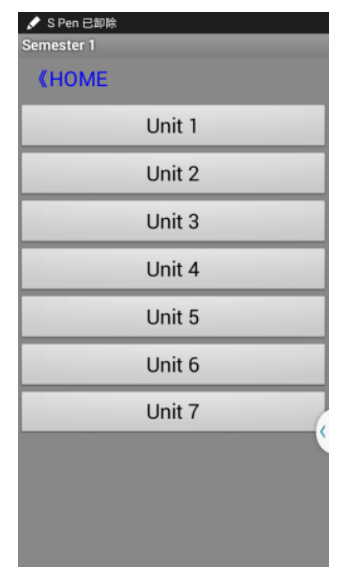

Fig. 4. Unit page in the app.

Finally, the researcher put the words and sentences in each unit, and they are shown in Fig. 5.

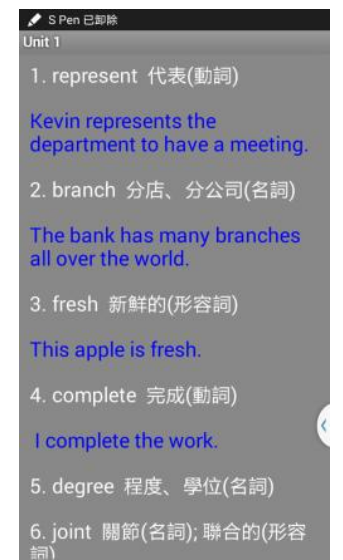

Fig. 5. Model sentences in the app.

\section{B. The Questionnaire of Students'Attitude toward the App}

The trail test was done in the researcher's English classroom, and a total of 30 students joined the study. In addition, the questionnaire for the students was designed by the author, and it consisted of 8 items (see Table I) to measure students' attitudes toward the use of NGSL app. Seven of the questionnaire items are 5-point Likert type scale while item number eight is an open-ended question (with " 5 " corresponding with strongly to " 1 " responses strongly disagree). The thirty pilot study questionnaires were collected and analyzed using SPSS 12.0. The Cronbach reliability of the questionnaire was 0.798 , which indicated good reliability of the questionnaire.

TABLE I: THE QUESTIONNAIRE OF STUDENTS’ ATTITUDE TOWARD THE APP

\begin{tabular}{ll}
\hline \hline Items & Descriptions \\
\hline 1 & I have more opportunities to learn English by using the app. \\
3. & It is easy to use the NGSL app. \\
4 & I am happy when I use the NGSL app. \\
5 & I feel relaxed when I use the NGSL app. \\
6 & I think I will use other educational app in the future. \\
7 & I am satisfied with the NGSL app. \\
8. & After using the NGSL app, I have the following comments: \\
\hline \hline
\end{tabular}

The study wanted to test four factors: students' willingness to use the app (items $1 \& 2$ ), students' affective factor toward the app (items $3,4 \& 7$ ), students' active use of the app (items $5 \& 6$ ) and students' opinions toward the app (item 8).

The overall averages of the study are between 3.33 to 4.10 , which indicate students' positive attitudes toward the app, and the statistics of the questionnaire are presented in Table II.

TABLE II: STATISTICS OF THE QUESTIONNAIRE

\begin{tabular}{ccc}
\hline \hline Items & Mean & SD \\
\hline 1 & 4.10 & 0.32 \\
2 & 3.81 & 0.36 \\
3 & 3.33 & 0.42 \\
4 & 3.92 & 0.35 \\
5 & 3.79 & 0.37 \\
6 & 3.81 & 0.36 \\
7 & 3.69 & 0.38 \\
\hline \hline
\end{tabular}

\section{DISCUSSIONS}

Using mobile devices in learning is very popular nowadays because it is portable with high mobility. In addition, when mobile devices are combined with the internet, teaching can be extended to outside the classroom, and learning can be done ubiquitously. Moreover, students are able to learn in a real context instead of receiving knowledge in the textbooks. Through social websites, like Facebook or Twitter, students can ask questions or interact with teachers more quickly. Initially, the designs of mobile apps were not for educational purposes. However, with the appropriate design, the apps can be teacher's teaching aid, and students' learning can be more multiple.

In this study, the designed vocabulary learning app aims to make students be more active in learning, control their learning progress and review what they have learned and this corresponds to the advantages of using technology in language learning [20]. This kind of "student-centered" teaching approach emphasizes the "real context" is very important in learning. In addition, in the constructivist classroom, the focus tends to shift from the teacher to the students, that is, students collaborate to discuss or share their ideas with the classmates. The learning environment is more important than the teaching environment. Hence, the study designs the app which is expected to help college students master their English learning and enhance their English ability.

With the proposed English vocabulary app, students can choose when and where to learn. The whole process is a student-centered learning. They can decide their learning path and review the weakness parts with the app.

According to Table II, we found that students found their motivation in learning English increased $(M=4.10)$, followed by "I feel relaxed when I use the NGSL app" (M=3.92). This may indicate that students have positive attitude toward the app. No wonder item 6 "I think I will use other educational app in the future" reached NO. $3(\mathrm{M}=3.81)$ because their English learning motivation has been improved and then they can become active learners to learn the language. However, item 3 reached the lowest score $(M=3.33)$, and this may be that students were relaxed to use the app, but they don't want 
to learn the language; hence, they are not happy to use the app. For most of the students, the main purpose to learn English would be passing the exams. Therefore, they are not happy.

In the questionnaire, item 8 is an open-ended question, "After using the NGSL app, I have the following comments:__." The following are some excerpts of the comments.

I think it's very convenient because I can use my smartphone to study the words. (S1)

I like to slide my finger on the screen and learn the words. (S2)

The sentences would show up after I tap the words, which is very interesting to me. (S5)

The interface is not very attractive. I don't like the color. It's too dull. (S6)

I think the pronunciation of the words and sentences can be added to the app because I like to listen to the pronunciation. (S7)

In the news section, I wish the teacher can add some supplementary information, such as jokes, slangs or songs. (S9)

I hope the teacher can make a game for us to practice the words in the app. (S10)

I wish the teacher can let us know each student's progress, and show us how many times we have tapped on the same words. It will help us review the words more efficiently. (S13)

As a passive learner, I feel happy to learn English words with the app. (S17)

I found that I learned more and I am more interested in learning English now. (S20)

\section{CONCLUSIONS AND SUGGESTIONS}

The study used the proposed English word app and the questionnaire to investigate college students' attitude toward English vocabulary learning. This is just a pilot study, and the conclusions and suggestions for future research are introduced as follows.

\section{A. Conclusions}

This paper proposed the self-developed English vocabulary app for college students to use in a private university in central Taiwan. The researcher designs bilingual interface and provides sample sentences for the target group. The conclusions of the study can be summarized as follows:

1) Increase students' use of educational apps

The proposed English app encouraged students' motivation in learning English vocabulary. Besides, they are more relaxed to learn with their smartphones.

2) Cultivate students' self-learning habit

The app helped students think more and use their smartphones to improve their self-learning habit.

3) Provide ubiquitous learning environment

According to the results of the pilot study, students felt that they could learn without space constraints.

4) Develop students' confidence in language learning

Based on the open-ended question, most of the students liked to use the app, and they thought it was interesting to use it. Moreover, some students felt it's more efficient to use the app in language learning. This also corresponds to the spirit of m-learning.

5) Achieve CTML goals

The design of the pilot study is in line with the CTML theory. That is, the app helps students' vocabulary acquisition, and the texts in the app can deliver content to students.

\section{B. Suggestions}

The pilot study designed an English vocabulary learning app in both Chinese and English interface. Based on the results, there are some limitations and suggestions for future research of the study.

1) There is no server to track the number of users.

2) The proposed app doesn't provide word pronunciation.

3) The proposed app is only valid for Android system and for those who use iOS are not able to use the app in this study.

In the future, if there are more funds, the researcher will track the number of users, add audio files, quizzes or dynamic assessment system to the app.

\section{ACKNOWLEDGMENT}

The research was supported by Feng-Chia University's teaching excellence program NO. 14C56601.

\section{REFERENCES}

[1] G. J. Robert, "Emerging technologies, mobile apps for language learning," Language Learning \& Technology, vol. 15, pp. 2-11, June 2011.

[2] C. M. Chen and Y. L. Li, "Personalized context-aware ubiquitous learning system for supporting effective English vocabulary learning," Interactive Learning Environments, vol. 18, no. 4, pp. 341-364, 2010.

[3] A. Littlejohn, A. Margaryan, and G. Vojt, "Exploring students' use of ICT and expectations of learning methods," Electronic Journal of e-Learning, vol. 8, no. 1, pp. 13-20, 2010.

[4] J. Lambert and P. Cuper, "Multimedia technologies and familiar spaces: $21^{\text {st }}$ century teaching for $21^{\text {st }}$ century learners," Contemporary Issues in Technology and Teacher Education, vol. 8, no. 3, pp. 264-276, 2008.

[5] J.M. Sykes, "Technology just playing games? A look at the use of digital games for language learning," The Language Educator, pp. 32-35, October, 2013.

[6] E. Peterson, "Internet-based resources for developing listening," Studies in Self-access Learning Journal, vol. 1, no. 2, pp. 139-154, 2010.

[7] R. F. AlCattan, "Integration of cloud computing and web 2.0 collaboration technologies in e-learning," International Journal of Computer Trends and Technology, vol. 12, no. 1, pp. 46-55, June, 2014.

[8] H. Zheng, "A virtual learning community based on cloud computing and web 2.0," International Journal of Computer Science Issues, vol. 9, no. 6, pp. 361-366, November, 2012.

[9] B. Xu, N. Wang, and C. Li, "A cloud computing infrastructure on heterogeneous computing resources," Journal of Computers, vol. 6, no. 8, pp. 1789-1796, 2011.

[10] S. H. Hung, C. S. Shih, J. P. Shieh, C. P. Lee, and Y. H. Huang, "Executing mobile applications on the cloud: framework and issues," Computers \& Mathematics with Applications, vol. 63, no. 2, pp. 573-587, 2012.

[11] C. M. Chen and C. J. Chung, "Personalized mobile English vocabulary learning system based on item response theory and learning memory cycle," Computers \& Education, vol. 51, no. 2, pp. 624-645, 2008.

[12] G. J. Hwang and H. F. Chang, "A formative assessment-based mobile learning approach to improving the learning attitudes and achievements of students," Computers \& Education, vol. 56, no. 4, pp. 1023-1031, 2011.

[13] O. Tabatabaei and A. H. Goojani, "The impact of text-messaging on vocabulary learning of Iranian EFL learners," Cross-Cultural Communication, vol. 8, no. 2, pp. 47-55, 2012. 
[14] H. C. Chu, G. J. Hwang, and C. C. Tsai, "A knowledge engineering approach to developing mindtools for context-aware ubiquitous learning," Computers \& Education, vol. 54, no. 1, pp. 289-297, 2010.

[15] B. Patten, I. A. Sa'nchez, and B. Tangney, "Designing collaborative, constructionist and contextual applications for handheld devices," Computers \& Education, vol. 46, no. 3, pp. 294-308, 2006.

[16] K. Shabani, M. Khatib, and S. Ebadi, "Vygotsky's zone of proximal development: instructional implications and teachers' professional development," English Language Teaching, vol. 3, no. 4, pp. 237-248, 2010.

[17] R. E. Mayer, Multimedia Learning, New York: Cambridge University press, 2001.

[18] M. J. Bishop and W. M. Cates, "Theoretical foundations for sound's use in multimedia instruction to enhance learning," Educational Technology Research and Development, vol. 49, no. 3, pp. 5-22, 2001

[19] R. E. Mayer and R. Moreno, "Nine ways to reduce cognitive load in multimedia learning," Educational Psychologist, vol. 38, no. 1, pp. $43-52,2003$
[20] J. P. Magliano, S. Todaro, K. Millis, K. Wiemer-Hastings, H. J. Kim and D. S. McNamara, "Changes in reading strategies as a function of reading training: a comparison of live and computerized training," Journal of Educational Computing Research, vol. 32, pp. 185-208, 2005.

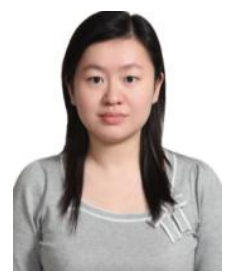

Bor-Tyng Wang is currently an assistant professor of Foreign Language Center at Feng-Chia University, Taiwan. She received her $\mathrm{Ph}$. D. degree in Graduate Institute of Educational Measurement and Statistics from National Taichung University of Education, Taiwan. Her research interests include dynamic assessment, knowledge structure analysis, English language teaching and CALL. She was also the associate executive editor of International Journal of Kansei Information. 